
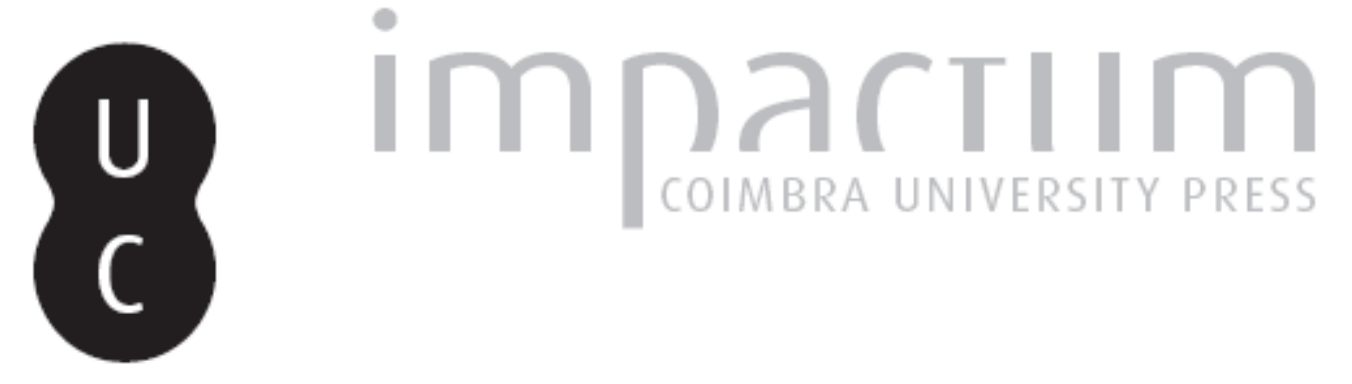

\title{
A percepção e representação em Maine de Biran
}

\author{
Autor(es): Umbelino, Luís António
}
Publicado por: Faculdade de Letras da Universidade de Coimbra, Instituto de Estudos Filosóficos

URL persistente:

URI:http://hdl.handle.net/10316.2/33334

DOI:

DOI:http://dx.doi.org/10.14195/0872-0851_37_4

Accessed : $\quad$ 26-Apr-2023 13:49:42

A navegação consulta e descarregamento dos títulos inseridos nas Bibliotecas Digitais UC Digitalis, UC Pombalina e UC Impactum, pressupõem a aceitação plena e sem reservas dos Termos e Condições de Uso destas Bibliotecas Digitais, disponíveis em https://digitalis.uc.pt/pt-pt/termos.

Conforme exposto nos referidos Termos e Condições de Uso, o descarregamento de títulos de acesso restrito requer uma licença válida de autorização devendo o utilizador aceder ao(s) documento(s) a partir de um endereço de IP da instituição detentora da supramencionada licença.

Ao utilizador é apenas permitido o descarregamento para uso pessoal, pelo que o emprego do(s) título(s) descarregado(s) para outro fim, designadamente comercial, carece de autorização do respetivo autor ou editor da obra.

Na medida em que todas as obras da UC Digitalis se encontram protegidas pelo Código do Direito de Autor e Direitos Conexos e demais legislação aplicável, toda a cópia, parcial ou total, deste documento, nos casos em que é legalmente admitida, deverá conter ou fazer-se acompanhar por este aviso.

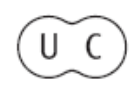




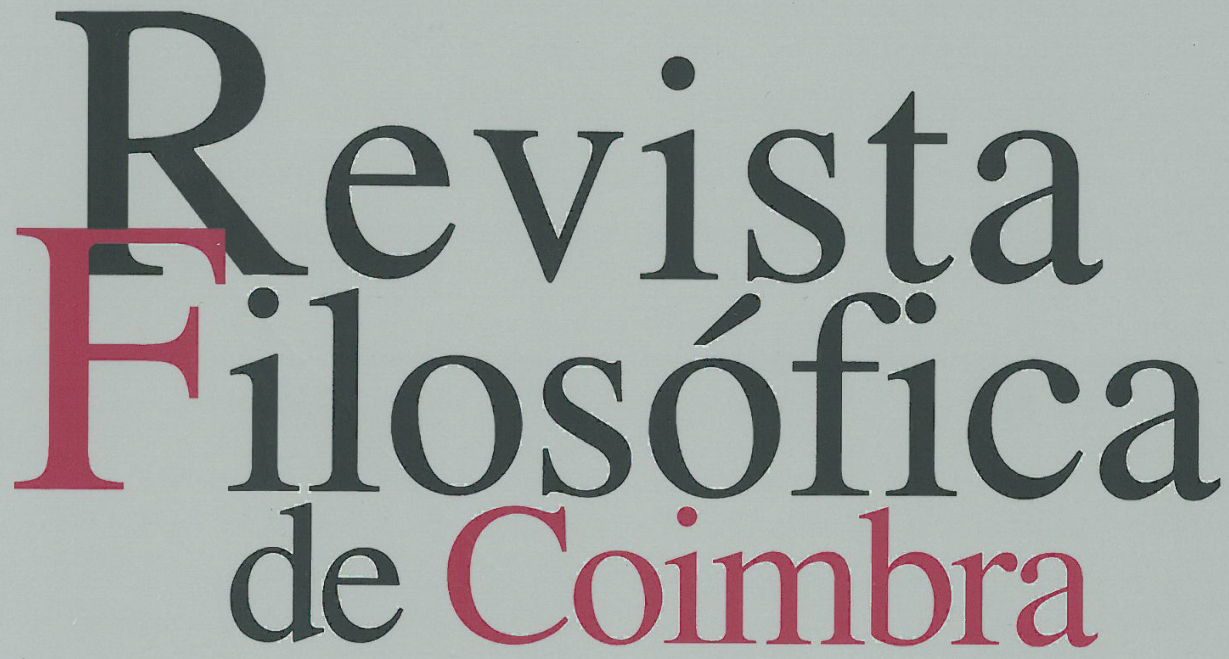

vol.19|n. $.37 \mid 2010$

Maria Luísa Portocarrero Mário Santiago de Carvalho Alexandre Franco de Sá Luís António Umbelino Luís G. Soto José Filipe Silva Joaquim Braga Maria da Conceição Camps Pedro Miguel Panarra Immanuel Kant 


\title{
APERCEPÇÃO E REPRESENTAÇÃO EM MAINE DE BIRAN
}

\author{
LUÍS ANTÓNIO UMBELINO*
}

Resumo: O presente trabalho pretende meditar sobre as implicações e o alcance da distinção biraniana entre apercepção e representação. Tentaremos mostrar que tal distinção: (a) se compreende no horizonte da teoria dos "pontos de vista", (b) se liga ao modo como Biran pensa o homem simplex in vitalitate, duplex in humanitate e (c) tem o seu centro na afirmação de que não há analogia entre factos "interiores" e "exteriores". Não terminaremos sem testar uma tese: a afirmação biraniana de um pensamento sem imagem tem por escopo filosófico guardar lugar para o problema da existência pessoal, num contexto histórico marcado pela tentativa de transposição da inspiração experimental para o âmbito da nascente science de l'homme.

Palavras-chave: Apercepção, relação, interior, representação, imagem, exterior.

Abstract: This paper aims to meditate on the implications and philosophical range of the distinction made by Maine de Biran between apperception and representation. We will try to show that the distinction in question: (a) must be understood in view of the philosopher's theory of "points of view", (b) that it should be linked to the idea of a man simplex in vitalitate, duplex in humanitate, and (c) that it has its centre in the statement that there is no analogy whatsoever between "interior" and "exterior" types of facts. Furthermore, we would like to test the following thesis: the biranian statement of a "thought without image" has an important philosophical goal, which is to try to give room to the problem of personal existence in an historical moment marked by the attempt to transport experimental methodologies to the field of the so called science de l'homme.

Key-words: Apperception, relation, interior, representation, image, exterior.

* Departamento de Filosofia, Comunicação e Informação (Faculdade de Letras da Universidade de Coimbra). 
1.

Ao recordar a sua dívida para com o pensador de Bergerac em Soimême comme un autre, $\mathrm{P}$. Ricoeur, com a economia de palavras que a meditação profunda permite, escreveu: "Maine de Biran é o primeiro filósofo a ter introduzido o corpo na região da certeza não representativa"'. Poderia ter acrescentado que o próprio modo como Biran pensa este âmbito de conhecimento não representativo, estabelecido sobre a linha do esforço aperceptivo, é também ele percursor e relevante, chamando renovadamente a pensar.

A actualidade da reflexão biraniana sobre o carácter irrepresentável dos factos que derivam da linha do esforço aperceptivo merece, efectivamente, ser sublinhada. P. Montebello já o notou, tendo demonstrado a que ponto tal reflexão permanece actual na contraluz do reconhecimento hodierno dos "impasses de uma teoria do conhecimento objectivo aplicado à subjectividade" 2 . Segundo Montebello, são vários os autores que, sem pretenderem reintroduzir ou sustentar um novo dualismo substancial, defendem, mesmo situando-se por vezes no seu horizonte, que fisicalismo, naturalismo ou materialismo são incapazes de conceber uma resposta totalmente convincente para o problema da "passagem entre a esfera subjectiva e o conhecimento objectivo." 3 Para este pensador francês, célebre comentador da filosofia biraniana, não é, pois, surpreendente que autores como J. Searle ou T. Nagel ${ }^{4}$, por exemplo, continuem a enfrentar o mesmo problema que, na sua raiz e no momento histórico em que se desenha, Maine de Biran lucidamente já enfrentava: o problema dos limites de qualquer movimento de objectivação e naturalização quando aplicado ao "espírito", à "subjectividade", ao "facto de consciência", ao "pensamento".

De facto, a garra e originalidade do pensamento de Biran - tal como se desenvolve, a partir de 1804, num claro afastamento em relação à escola de Condillac e ao horizonte estrito da idéologie ${ }^{5}$ - pode medir-se, antes de mais, pela ideia de que o solo do pensamento é o sentimento sui generis de um acto irrepresentável que coincide com a apercepção de si. Tal acto não é outro senão a relação de esforço, cujos elementos, distintos mas não

\footnotetext{
${ }^{1}$ RICOEUR, P., Soi-même comme un autre, Seuil, Paris, 1990, p. 372.

${ }^{2}$ MONTEBELLO, P., "Une individuation de la connaissance psycho-physique", in PETIT, Jean-Luc, Les neurosciences et la philosophie de l'action, Vrin, Paris, 1997, p. 81.

${ }^{3}$ Ibidem, p. 81.

${ }^{4}$ Ibidem, 81-82.

${ }^{5}$ A correspondência com Destutt de Tracy é, a este respeito, particularmente esclarecedora. Veja-se MAINE de BIRAN, Correspondance philosophique, 1766-1804, in ID, Oeuvres de Maine de Biran (dir. F. Azouvi), t. XIII-2, Vrin, Paris, 1999, pp. 266 e ss.
} 
separados, são uma força dita hiperorgânica e um corpo interiormente resistente $^{6}$. Nesta relação se atesta, interiormente e sem imagem (num interior polémico porque tocado pelo corpo) o existir pessoal que reclama, para ser conhecido, que nos concentremos sobre "o ponto de vista do sentido interno" e suspendamos tudo o que se pode "imaginar" (leia-se: representar à maneira do que está fora de nós e apenas se pode ver ou tocar $^{8}$ ) sobre o sujeito consciente. A individualidade pessoal e todos os modos activos nascem dessa dualidade primitiva, o que faz do "eu" não substância ou princípio lógico, mas acto, indivisível unidade na diferença de uma força de vontade e de uma resistência muscular, de uma causa que não se perde no seu efeito e de um efeito que se retoma na sua causa. O sentimento do esforço funda a experiência interior de mim que, então, se conquista na relação, mantendo-se irredutível a qualquer um dos elementos que a estruturam e dos quais, justamente, nada se pode saber em separado. A noção de relação é aqui fundamental: o solo da apercepção, da consciência de si, do pensar(-se) coincide com o sentimento do próprio perseverar activo. E tal certeza, precisamente, é primeiro testemunhada pelo sentido íntimo e não representada. Assim, à afirmação de que um sentido íntimo nos dá o conhecimento interno de tudo o que fazemos e sentimos, deve corresponder a preocupação pela distinção de tal tipo de conhecimento, de tal fonte de evidência, do modo de conhecer próprio dos sentidos exteriores. No estudo homem devemos ponderar duas fontes de evidência (interior e exterior) e dois tipos de conhecimento: representativo para o que se pode "ver" e "tocar"; reflexivo (seguindo a linha da apercepção) para o que "se liga inteiramente a esses modos mais íntimos, que não têm, fora da consciência, signos que os manifestem, nem objecto ou imagem que os coloquem num relevo sensível." 9

${ }^{6}$ Cf. MONTEBello, P., Nature et subjectivité, Millon, Grenoble, 2007, p. 23.

${ }^{7}$ MAINE de BIRAN, Commentaires et marginalia, Dix-septième siècle, in ID, Oeuvres de Maine de Biran (dir. F. Azouvi), t. XI-1, Vrin, Paris, 1990, p. 86.

${ }^{8}$ MAINE de BIRAN, Discours à la société médicale de Bergerac, in ID, Oeuvres de Maine de Biran (dir. F. Azouvi), t. V, Vrin, Paris, p. 50. (citado Discours). Cf. AZOUVI, F., Maine de Biran. La science de l'homme, Vrin, Paris, 1995, pp. 75-76 ; 154-155.

${ }^{9}$ Discours, p. 50. «L'imagination, qui, représentant ce qui est hors de nous, s'attache exclusivement, dans la formation de ses tableaux, à ce qui peut se voir, se toucher, se décrire» implica um tipo de análise que é representativa, ou seja, de descrição exterior será este o modelo seguido pelo método das ciências anatómicas e fisiológicas; por outro lado, «la réflexion qui, se concentrant sur ce qui este n nous, s'attache tout entière à ces modes les plus intimes, qui n'ont point, hors de la conscience, de signe de manifestation, ni d'objet ou d'image qui les mette dans un relief sensible» será o tipo de análise que deverá ser aplicado exclusivamente ao âmbito de uma ciência das ideias e das faculdades do sujeito pensante, melhor, a uma ideologia subjectiva. Veja-se igualmente MAINE de 
O reconhecimento de tais distinções reclama e justifica, segundo Biran, que se marque bem a especificidade do ponto de vista interior, e se compreenda a razão da sua irredutibilidade ao ponto de vista exterior. Entenda-se esta atitude combativa da filosofia biraniana: no momento histórico em que se assiste à transposição da inspiração experimental para o âmbito de estudo "dos princípios e começo do pensar", à época em que tal transposição anuncia uma avassaladora uniformização epistemológica e promete submeter todo o âmbito da novel ciência do homem à exclusiva partilha de clareza e de precisão própria ao método das ciências naturais $^{10}$, Biran procura guardar lugar para o problema da existência pessoal, através da afirmação de um âmbito de factos - aperceptivos, conscientes - propriamente humanos. O filósofo viu com clarividência o fascínio crescente exercido sobre a maioria dos espíritos do seu tempo pela "excelência" dos resultados apresentados pelo "método da experiência"; e compreendeu que o extenso e rigoroso conjunto de sucessos de tal método, as "verdades práticas" a que conduziu, o desenvolvimento que imprimiu ao "exercício das faculdades" não poderia ter deixado de produzir uma influência imparável sobre os mais variados âmbitos de estudo. Ante as inúmeras vitórias de semelhante método, não poderiam certamente muitos deixar de pensar em promover a inclusão na sua esfera do "sistema inteiro dos conhecimentos humanos"11. Ora, justamente, nessa tentativa de transposição da análise experimental para o estudo do homem, que em acordo com o espírito do tempo se fomentará, tornam-se segundo Maine de Brian tão evidentes quanto preocupantes os sintomas de crise da nascente ciência do homem.

BIRAN, Mémoire sur la décomposition de la pensée (versão premiada), in ID, Oeuvres de Maine de Biran (dir. F. Azouvi), t. III, Vrin, Paris, 1988, pp. 304-305 (citado Décomposition). Mesma tese, entre outras ocorrências, em MAINE de BIRAN, Dernière philosophie: existence et anthropologie, in ID, Oeuvres de Maine de Biran (dir. F. Azouvi), t. X-2, Vrin, Paris, 1989, p. 22.

${ }^{10} \mathrm{Cf}$. MAINE de BIRAN, De l'aperception immédiate. Mémoire de Berlin,1807, in ID, Oeuvres de Maine de Biran (dir. F. Azouvi), t. IV, Vrin, Paris, 1995, p. 6 (citado De l'aperception): «Si l'on suit ses conquêtes depuis Bacon, on verra son influence progressive s'étendre successivement sur les genres d'études les plus divers, et finir par embrasser dans sa sphère le système entier des connaissances humaines, la métaphysique des esprits comme la physique des corps, la science des abstraits et la science des concrets». Cf., num mesmo sentido e entre outras ocorrências da mesma tese, MAINE de BIRAN, Rapports du physique et du moral de l'homme, in ID, Oeuvres de Maine de Biran (dir. F. Azouvi), t. VI, Vrin, Paris, 1984, p. 3 (citado Rapports); MAINE de BIRAN, Essai sur les fondements de la psychologie et sur ses rapports avec l'étude de la nature, I, in ID, Oeuvres de Maine de Biran (dir. F. Azouvi), t. VII-1, Vrin, Paris, 2001, pp. 72-73 (citado Essai, I).

${ }^{11}$ De l'aperception, p. 6. 
Biran apontará esses sintomas através de uma série de questões precisas: sem nunca deixar de reconhecer - porque não é disso que se trata - o vigor, a utilidade e o valor do método das ciências da natureza, não deverá "uma ciência do começo do pensar" ponderar criticamente a aplicação de um método representativo e generalizador a uma ordem de factos que permanece interior e individualizada? Não será questionável que uma ciência das faculdades próprias do sujeito pensante se pretenda desenvolver sem investigar como começa o pensamento para alguém, sem procurar a base - interior e irrepresentável - sobre a qual "o sujeito se pode apoiar para reagir sobre si próprio, conhecer o princípio das operações íntimas, atribuir a fonte real e primitiva das suas ideias, saber enfim como, a que título e através de que encadeamento ou conjunto de condições e de circunstâncias, se encontra actualmente constituído pessoa individual e inteligente" "12? Não será contraditório que uma ciência que pretende ser $d o$ homem se proponha seguir um caminho que ilude o problema da origem das faculdades, da sua individualização (primeiro testemunhada intimamente e redobrada reflexivamente) e, finalmente, do que permite a alguém dizê-las suas?

Uma ciência do homem - concluirá Biran - não poderá deixar de ser em tudo diferente daquela que se aplica aos objectos exteriores; dito de outro modo: na medida em que não pode deixar de se constituir como ciência das faculdades ou operações primeiras da inteligência, a investigação do propriamente humano do homem não pode e não deve "ser exclusivamente submetida aos procedimentos das outras ciências experimentais, e sujeita a tomar, como elas, os seus dados primeiros das aparências sensíveis do mundo fenomenal."13 Aqueles que o jugam possível são os mesmos que equivocamente acreditam que todas as questões relativas aos humanos se resolvem no momento em que se explicam as suas traduções exteriores. Mas, precisamente, segundo Brian, ignoradas as diferenças, não questionado o problema que encerra a passagem do interior apercebido ao exterior representado torna-se impossível alcançar um conhecimento que respeite os factos na sua especificidade. E, no entanto, o ar do tempo - ar condillaciano, idéologique, onde permanece a influência de Bacon, "imortal restaurador da verdadeira filosofia" e do âmbito da psicologia, de Locke, transformador da metafísica em genealogia e filiação do nosso conhecimento, de Newton, percursor do gesto característico de unificação da multiplicidade dos fenómenos numa lei ou princípio tendencialmente universal, da fisiologia cujos resultados se conquistam no

\footnotetext{
12 Ibidem, p. 7

13 Ibidem, p. 8
} 
campo estrito dos dados do conhecimento sensível ${ }^{14}$ - julga-o triunfantemente possível. Biran discordará: o método que convém ao estudo dos fenómenos que se representam, quando aplicado ao estudo do humano numa ciência do homem, violenta inevitavelmente os factos que, ocorrendo no humano, se fazem presentes apenas na linha do esforço aperceptivo, não podendo ser localizados ou encontrados num qualquer relevo sensível. A exploração do fenómeno de consciência, do modo de ser singular, da ordem propriamente aperceptiva e respectivo momento ontogenético requer um método próprio, distinto do método das ciências da natureza - um método assente num ponto de vista interior que seja capaz de dar conta do que nenhuma análise exteriorizante está em condições de considerar: a complexidade do homo duplex.

\section{2.}

A linha do esforço, do facto de consciência, do exercício das faculdades activas, do pensamento é, segundo Biran, recorde-se, questão de uma relação primitiva: aquela que une, enquanto termos distintos mas não separados ${ }^{15}$, uma força da vontade e a resistência interiorizada de um corpo próprio. $\mathrm{O}$ "eu" não é, pois, uma força, nem é um corpo resistente; não é uma energia hiperorgânica e não é um corpo orgânico: o "eu" é a própria relação sentida de uma força que se recupera no corpo resistente e de um corpo que resiste porque coexiste com a força da vontade. Ora, neste sentido - eis o decisivo - não se percebe, entende Biran, como pode suporse (evidente reabilitação do dualismo mais obscuro) que a ordem "interior", aperceptiva, consciente, activa, pessoal, dual que tem nessa relação o seu começo possa ser de algum modo encontrada num "exterior" físico-fisiologicamente apreendido. E, no entanto, é neste caminho que a nascente ciência do homem se vai comprometer, trilhando a via de uma identificação da psicologia à física e a fisiologia. No momento em que a revolução física do conhecimento cedo fará predominar sobre a ciência do homem um paradigma físico-fisiologista, uma opção acrítica fundamental é, então,

14 Para uma contextualização histórica, cf. GUSDORF, G. La conscience révolutionnaire, Payot, Paris, 1978; ID, Les principes de la pensée au siècle des Lumières, Payoy, Paris, 1971; MORAVIA, Sérgio, Il tramonto dell'iluminismo, Filosofia e Politica nella societá francese (1770-1810), Laterza, Bari, 1968; MADINIER, Gabriel, Conscience et mouvement: étude sur la philosophie française de Condillac a Bergson, Félix Alcan, Paris, 1938; GOUHIER, H., Études sur l'histoire des idées en France depuis le XVIIe siècle, Vrin, Paris.

${ }^{15}$ Cf., por exemplo, Essai, I, p. 9. 
sancionada: a de que é possível tudo representar do humano, tudo reduzir a imagem, tudo generalizar, tudo tornar visível - como se o interior apercebido das faculdades e a génese e realidade do pensamento pudessem ser integralmente cartografados, lidos no exterior deles próprios num qualquer facto manifesto e observável, num qualquer corpo forçado a coincidir com a sua própria exterioridade. Assim, justamente, Biran não se cansará de o denunciar, desmantela-se e deturpa-se aquilo mesmo que se deveria querer estudar. Por não se ter precavido da física ${ }^{16}$, sustentará o filósofo de Bergerac, a ciência que deveria estudar as operações ou modificações próprias do sujeito pensante trilhará os caminhos do seu efectivo esquecimento, traindo a necessária consideração real da génese do pensar e da subjectividade aperceptiva, da singularidade pessoal e da vivência, da complexidade psicológica e da reflexão de si.

Tais considerações não devem ser interpretadas, todavia, como mera crítica cega e retrógrada à ciência do seu tempo, que Maine de Biran conhecia e admirava. Alguns dos seus cultores mais celebrados foram, aliás, seus interlocutores intelectuais. Biran estudou em detalhe os textos de Bichat, Cabanis, Bonnet, Buffon e Barthez, seguiu as investigações de Hartley, Willis e Gall, leu minuciosamente os trabalhos Pinel, descobriu os trabalhos de Reil e meditou, antes de morrer, os trabalhos de Magendie. Conhecia muito bem o conjunto das ciências médicas da sua época e tais conhecimentos foram reconhecidos não só pelos médicos, filósofos e profissionais de saúde que o elegeram Presidente da Sociedade Médica de Bergerac, como também pelo célebre A. Royerd-Collard, que recorreu ao amigo de Gratelup para orientação quando assumiu funções na então recém-criada Cátedra de Medicina Mental em Paris. Biran tem sempre o cuidado de salvaguardar o vigor e a importância das novas conquistas científicas. As suas reservas não são, pois, em relação à ciência em si; outrossim incidem sobre o facto de a avassaladora incursão do método da física no âmbito do estudo do homem não parecer capaz de medir ou sequer compreender o que, epistemologicamente, se propõe fazer. É o reconhecimento dos limites de aplicação da inspiração experimental que, efectivamente, está em causa para Biran, na contraluz do projecto audacioso de redução de todo o tipo de fenómenos (orgânicos, intelectuais) a uma mesma hipótese explicativa, a um mesmo tipo de encadeamento causal, a um mesmo ponto de vista.

${ }^{16}$ Rapports, p. 5: «C'est en ayant égard sans doute à cette contrariété dans la tendance et moyens des deux sciences que Newton, touchant le nœud de la question qui nous occupe, s'écriait ô physique! préserve-toi de la métaphysique; c'est aussi en ayant égard à l'observation nécessairement double des deux classes de phénomènes, dont le mélange et la confusion offrent tant d'erreurs et d'illusions et de mécomptes, que nous pouvons nous écrier à notre tour, ô psychologue! préserve-toi de la physique.» 
Cedo na sua Mémoire sur la décomposition de la pensée, o filósofo será claro na necessidade de traçar tais linhas de demarcação, único modo de evitar a violência feita aos factos interiores que, não tendo qualquer afinidade com os factos observáveis, são irredutíveis à explicação representativa. Seria adequado - escreverá então - que "se distinguisse sempre na expressão como na realidade" pontos de vista tão diferentes como aqueles que permitem considerar "um fenómeno tomado somente nos seus signos exteriores, ou na sua relação à consciência" 17 e que, para cada um desses pontos de vista se encontrasse o método adequado. Efectivamente, nenhuma analogia pode, segundo Biran, encontrar-se entre factos cujos efeitos se apercebem ou se reflectem unicamente no sujeito pensante e aqueles que se conhecem representativamente em signos exteriores ${ }^{18}$. Considere-se, para o ilustrar, o exemplo básico de um movimento corporal: parece evidente a Biran que aquele que o exerce tem necessariamente o sentimento imediato de ser a sua causa nesse corpo, não reclamando tal evidência que conheça "objectivamente as fibras nervosas" que entram em jogo em tal situação. Ao contrário (como a fenomenologia contemporânea do corpo confirmará), a própria possibilidade de um movimento voluntário depende mesmo de permanecermos na ignorância desse "corpo do anatomista ou do fisiólogo"19, pois se no momento de agir fosse necessário representar os respectivos instrumentos, pensar em cada um e percorrer as respectivas ligações, "a vontade jamais nasceria." 20 Que as condicionantes orgânicas estejam presentes, não invalida que a força da vontade "seja a própria causa eficiente dos movimentos que ela produz" 21 e que, consequentemente, tenhamos do exercício da vontade, aplicada não a um órgão ou músculo mas existindo em relação a um corpo interiormente resistente e sem figura, um saber evidente que não se confunde com a explicação das condicionantes orgânicas. As ligações nervosas, o sistema muscular, o cérebro, são certamente necessárias ao movimento voluntário, como o são aliás dos movimentos involuntários; mas apenas a força da vontade (e o

17 Décomposition, versão premiada, p. 37.

18 Ibidem, p. 33.

${ }^{19}$ HENRY, M., Philosophie et phénoménologie du corps, P.U.F., Paris, 1987, p. 87. Esta passagem é igualmente sublinhada por MONTEBELLO, P. La décomposition de la pensée. Dualité et empirisme transcendantal chez Maine de Biran, Millon, Grenoble: Million, 1994, p. 161.

${ }^{20}$ Essai, I, p. 164; Cf. MAINE de BIRAN, Commentaires et marginalia, Dix-huitième siècle, in ID, Oeuvres de Maine de Biran (dir. F. Azouvi), t. XI-2, Vrin, Paris, p. 60 (citado Commentaires XVIII).

${ }^{21}$ MAINE de BIRAN, Commentaires et marginalia, Dix-neuvième siècle, in ID, Oeuvres de Maine de Biran (dir. F. Azouvi), t. XI-3, Vrin, Paris, p. 62 (citado Commentaires XIX). 
corpo próprio que lhe co-responde) é condição suficiente dos primeiros. Ou seja: se suprimirmos as primeiras condições, nem movimentos voluntários nem movimentos involuntários serão possíveis; se suprimirmos a vontade em relação com o seu distinto mas não separado plano de consistência, teremos a possibilidade de movimentos involuntários, mas não de movimentos voluntários. Supor o contrário equivaleria a afirmar que não há um corpo apropriado à vontade, ou que apenas aqueles que conhecem as condições fisiológicas de determinadas capacidades poderiam dispor da vontade $^{22}$. Na verdade o que, segundo o filósofo de Bergerac, urge reconhecer é o facto de no homem, a simplicidade vital, a organização e as suas leis, subsistirem complicadas de uma ordem hiper-orgânica, psicológica, subjectiva que lhe está ligada mas que, em rigor, lhe é - de facto e, consequentemente, também de um ponto de vista epistemológico - irredutível. O homem é simples na vitalidade, mas duplo na humanidade ${ }^{23}$ : nele se entrecruzam uma ordem físico-fisiológica, cujos factos são acessíveis a uma explicação representativa e generalizadora, e uma ordem de factos que, apesar das suas correlações com a simplicidade, correspondem a uma simplicidade de outra ordem: a da individualidade pessoal consciente, ordem de uma unidade dual aperceptiva.

Antecipando a fértil distinção metodológica de Dilthey entre a explicação da vida e a compreensão do homem, fundadora das denominadas ciências do espírito e importante momento da história da hermenêutica filosófica, Biran considera que o que se passa na dualidade não se compreende à maneira do que se passa na simplicidade: podemos explicar a simplicidade; mas se explicar significar forçar um facto a manifestar-se num exterior que não é ele (e, portanto, o deturpa), então a dualidade não se explica, antes reclamando um método reflexivo ${ }^{24}$ (que não introspectivo) de compreensão, já que o que se passa em mim ou é de mim, precisamente, apenas se faz presente ao sentido íntimo e, por isso, "não se pode provar de outro modo senão pelo seu testemunho" 25 . É certo que a complexidade do homo duplex não deixa de manter subtis e secretas negociações com a simplicitas da vitalidade, sendo proveitoso "reunir com sucesso todas as

22 Cf. Commentaires XVIII, p. 66. Seria supor, por exemplo, que apenas os oftalmologistas, únicos a conhecer com rigor o funcionamento do aparelho visual, poderiam ver. Cf. Essai, I, pp. 164; 166. Cf. MONTEBELlO, P., La décomposition..., o. c., p. 161.

23 Trata-se da expressão, recorrentemente citada por Biran, de BOERHAAVE, Herman, Praelectiones academicae de morbis nervorum, Leyde, 1761, t. II, p. 497. "Ergo homo est duplex in humanitate, simplex in vitalitate".

${ }^{24}$ Ibidem, p. 45. Nosso sublinhado.

${ }^{25}$ De l'aperception, p. 8. 
luzes teóricas e todos os dados de uma dupla observação interior e exterior." 26 Mas deve acrescentar-se que "ao fazer assim concorrer os dois métodos, seria extremamente perigoso confundir os respectivos limites e resultados, ou virar ao contrário a ordem da sua aplicação e do seu emprego, de tal maneira que se tratasse com um o que é do âmbito do outro." ${ }^{27}$ A tarefa de traçar limites deverá servir, pois, desde logo, para sublinhar que quando se passa de um ponto de vista exterior para um ponto de vista interior, de um facto observável para um facto de sentido íntimo, da generalização explicativa para individualização aperceptiva, os problemas mudam de natureza, os factos mudam de ordem, as realidades são distintas, a fonte de evidência varia, o encadeamento causal é diverso. Mas também deverá servir para denunciar a que ponto o apagamento de tais diferenças resultará, na prática, num insustentável menosprezo pela complexidade do humano, pela realidade pessoal do pensamento e do corpo próprio, pela dimensão subjectiva da individualidade aperceptiva, pelo carácter interior da dualidade que funda o propriamente humano do homem.

\section{3.}

$\mathrm{Na}$ tentativa de transposição abusiva do que é interior para o exterior ignora-se a própria base real da individualidade pessoal consciente e subverte-se a relação psico-física. A originalidade de Biran está em reconhecer, justamente, que o continente inexplorado do sentido íntimo existe por força da ligação (e na relação, portanto) entre vontade e corpo, não se encontrando, por conseguinte, nem no cérebro, nem nos músculos, nem em qualquer outro "lugar" da organização orgânica. A possibilidade de algo como o pensamento ou a apercepção é, pois, um acto que seguramente não se compreenderá nos quadros equívocos dos dualismos metafísicos substancialistas, nem à luz dos seus principais reflexos no campo científico, a saber: a tendência para a "auto-objectivação da verdade" 28 e para a absolutização dos factos, a opção pelo primado da generalização representativa, a defesa cega de um paradigma da manifestação ou da exteriorização e a consequente tentativa de apagar a diferença ontológica entre factos de sentido íntimo e factos exteriores.

O esforço é a resposta de Maine de Biran a tal paradigma que tende a "fixar" e a decompor objectivamente o seu âmbito de estudo: o princípio real do pensamento atesta-se na "concepção reflexiva de uma força que

\footnotetext{
${ }^{26}$ Rapports, 152

27 Décomposition, versão premiada, p. 49.

${ }^{28}$ Cf. MONTEBELLO; P., "Une individuation”..., o. c., p. 79.
} 
apenas se torna viva ou consciente dela própria pelo seu desenrolar actual sobre o seu termo de aplicação apropriado" 29 ; a consciência de si, que é o primeiro "produto" desta relação primitiva, mas igualmente todas as variações e diferenciações das faculdades e dos modos propriamente humanos se constituem a partir dessa dualidade primitiva e dos modos como vontade e corpo se conjugam. Tal estrutura do esforço acompanhará, pois, todos os modos activos do existir consciente ligando-os ao meu destino pessoal. Ora, se são apercebidos e distinguidos reflexivamente, tais modos não poderão deixar de ser adulterados quando se pretender encontrálos representativamente, ou seja, num exterior generalizado e distinto do âmbito da individualidade apercebida. É por esta razão que Biran não poderia deixar de interrogar, com evidentes reservas, o nascimento do avassalador projecto de naturalização e biologização do humano que reconhece ganhar terreno no seu tempo. E é pela mesma razão que em tal projecto não poderia deixar de arguir a hipótese segundo a qual tudo mesmo o pensamento - se deve poder reportar univocamente ao objecto da "ciência favorita", de tudo se poder explicar como físico, ou seja, "da mesma maneira, com as mesmas concepções" estabelecidas sobre o jogo especular de imagens físicas.

Para Biran é contudo evidente que o "pensamento" não começa no lugar onde alguém o pretende observar, mas existe já no exercício de si do observador; a investigação do seu momento ontogenético representa, pois, uma questão realmente de princípio para uma ciência do homem: ciência que, se deve "saber fisiologicamente o que é uma impressão, um movimento, uma percepção", não pode deixar de, também e fundamentalmente, saber "determinar como uma impressão é experimentada, como uma ideia é pensada, como um sujeito é possível" 30 . Por igual precipitadas pelo afã de exteriorizar fisio-simbolicamente, as doutrinas do tempo de Biran não se detêm neste problema, julgando-o resolvido do lado do observável. A Cabanis, e à sua idéologie fisiológica, por exemplo, o uso equívoco da palavra sensação permite tomar as funções ou movimentos dos órgãos por causas dos fenómenos intelectuais, propondo a possibilidade de estudar o pensamento no cérebro como a digestão no estômago. Bonnet, por seu turno, defende que tais funções e movimentos dos órgãos são signos naturais adequados a representar os fenómenos da inteligência e da vontade, mais precisando - na convicção de que a física é a mãe da metafísica ${ }^{31}$ -

\footnotetext{
${ }^{29}$ Décompoition, versão premiada, p. 125

${ }^{30}$ MONTEBELLO, P., La Décomposition...o. c., p. 76.

31 Rapports, p. 39
} 
que o pensamento mais não é do uma abreviatura completa do Género Nervoso, ou seja, não é senão uma "neurologia em miniatura"32. Gall atrever-se-á a ir muito mais longe: a frenologia representará um protocolo de observação que pretenderá localizar, sistematicamente e para lá de qualquer dúvida, as faculdades intelectuais não apenas em zonas cerebrais mas sobre a estrutura orgânica palpável do crânio. Neste excesso se torna mais claro o que verdadeira e exclusivamente motiva a doutrina de Gall e todas as hipóteses do mesmo género: o sonho de ver o pensamento ${ }^{33}$, tocar as faculdades mais interiores, ler em "signos puramente exteriores" o propriamente humano do homem, mapear para lá de qualquer dúvida a ligação entre as faculdades mentais e o cérebro, palpar enfim o moral no físico.

Não se detendo no problema da passagem entre físico e moral, objectivo e subjectivo, não supondo sequer necessário investigar o "conhecimento do fundamento das relações que ligam os signos às coisas significadas" 34 , tais doutrinas são incapazes de dar conta do homo duplex. Tudo nelas conduz à simplicidade orgânica - como se a duplicitas não pudesse e não fosse de facto conhecida no seu princípio, na sua base real, no exercício individualizado de si. Configurarão por isso aquilo a que poderíamos chamar - recorrendo à expressão justa e feliz de P. Montebello - de metafísica da manifestação: paradigma de um conhecimento absoluto e tendencialmente despersonalizado do humano.

Os traços distintivos de tal paradigma da representação exteriorizante - que Biran reconheceu estar condenado a durar - foram bem identificados pelo filósofo de Bergerac. O primeiro desses traços encontra-se na suposição de que uma explicação integral do pensamento é possível a partir de um desdobramento expositivo e espacial nas respectivas condições orgânicas ou materiais. Tal "empirismo ilusório" 35 sustenta-se num dualismo objectivista, que presume melhor conhecido o que é do eu fora do eu, numa qualquer imagem representativa - como se os factos do sentido íntimo pudessem receber um maior grau de esclarecimento fora ou independentemente da sua fonte real, a saber aquele pode "dizer eu e dar um sentido [reflexivamente conquistado] a essa palavra" 36 . Presume-se assim o que, para Biran, é uma violência desnecessária feita aos factos: que o reflexivamente apercebido na linha inaugurada pelo esforço é melhor

\footnotetext{
32 Ibidem, p. 62.

${ }^{33}$ Cf. Discours, p. 50.

${ }^{34}$ Rapports, p. 73.

35 Ibidem, p. 84 .

${ }^{36}$ Essai, I, p. 77.
} 
conhecido numa generalização exteriorizante, que a própria individualidade aperceptiva é acessível primeiro à análise do observador perito.

Um segundo traço típico de tal conhecimento absoluto consiste em "inverter definitivamente a ordem de invenção do pensamento" ${ }^{37}$, ou seja, em supor acriticamente que o pensamento, a consciência, a apercepção, estão já feitos e acabados quando se começa a explicá-los. Assim se presume e se erige em base científica uma ilusão e uma mentira, a saber: que entre a atitude do observador exterior (que traça sobre um qualquer relevo sensível as imagens do pensamento) e a posição activa do sujeito consciente de si (que descobre o pensar no próprio acto perseverante de ser) haveria uma qualquer coincidência possível. Para Biran, tal possibilidade simplesmente não existe: uma actividade interiormente exercida - como é o pensamento não é traduzível por uma forma objectiva estática e totalmente manifesta; ou seja, "os modos, ideias ou actos que entram no entendimento" não podem "ser submetidos igualmente a um ponto de vista exterior e aprendidos nos traços materiais das impressões recebidas" 38 porque entre uns e outros não há qualquer analogia. O que não significa, deve notar-se, que, na sua base real, os factos interiores, permanecendo inexplicáveis (se explicar significa tornar visível), não sejam já sempre reflexivamente conhecidos.

Terceiro traço: presumir que o uso dos mesmos termos em campos de análise distintos corresponde à análise de uma mesma realidade. De um modo ou de outro, todas as doutrinas criticadas por Biran assentam neste gesto ao fazerem as suas "incursões no terreno da metafísica" 39 , ou seja, ao procurarem explicar as faculdades humanas: primeiro tomam do costume, da cultura que é a sua, palavras como pensamento, memória, raciocínio, etc.; pressupõem depois desnecessário analisar o respectivo fundamento e valor reflexivo pelo que o suspendem; operacionalizam de seguida esses termos e, finalmente, conduzidos pelo pressuposto de que se apenas se pode conhecer o que a imaginação pode localizar ${ }^{40}$, transpõem esse mesmo termo para a ordem dos factos observáveis, passando a presumir que o mesmo termo designa a mesma realidade de onde inicialmente foi tomado. E assim se promove "uma assimilação ilusória, perpetuamente estabelecida entre os fenómenos do $e u$ individual, [que por não serem reflexivamente aprofundados, permanecem] desconhecidos na sua natureza, no seu carácter, e no seu sentido próprio, com uma outra ordem de factos absolutamente estranhos ao $e u^{\prime \prime 4}$.

\footnotetext{
${ }^{37}$ MONTEBello, P., "Une individuation... », o. c., p. 91.

${ }^{38}$ Décomposition, versão revista, p. 326.

39 Discours, p. 48

${ }^{40}$ Cf. Discours, p. 50.

${ }^{41}$ Rapports, p. 86.
} 
Ao assumir-se, deste modo, sobre o pensamento um ponto de vista exterior ao próprio sujeito que pensa, reduzindo-o assim a uma representação especular, é o "modelo interior" que se perde de vista, é a sua base real que se ilude e o seu critério que se ignora - o critério da reflexão concentrada que opera sobre os "actos da sensibilidade e do pensamento" 42 acompanhando a variabilidade intensiva do esforço. Por isso, justamente, "o modo como uma organização qualquer, sempre concebida ou imaginada como extensão divisível e composta, pode ser ligada a um sujeito pensante, a um eu reflexivo, essencialmente um e simples, será o eterno escolho" de todas as doutrinas que "o tentam explicar" 43 . Desde logo porque tal tentativa de explicação pressupõe o estabelecimento de um paralelo ilusório entre os "fenómenos do eu" e os factos "concebidos no espaço". Tal paralelo, segundo Biran, deriva do facto de tais doutrinas não terem sabido "deduzir da própria natureza das nossas faculdades, ou dos nossos modos de conhecer, o princípio ou a razão da heterogeneidade absoluta das duas espécies de ideias primitivas (...) com as quais nos é permitido conceber, por um lado o sujeito pensante e as suas operações, por outro os órgãos materiais, o seu jogo e os objectos aos quais se aplicam." 44 Seria preciso que tais doutrinas da manifestação se detivessem no que opõe o método fisicalista ao método reflexivo ou psicológico, a observação exterior à apercepção interna, a classificação generalizante à individualidade pessoal. Verificariam, então, que a individualidade que resulta da decomposição objectiva dos fenómenos localizáveis nos órgãos que são os seus centros não guarda qualquer analogia com a individualidade aperceptiva. Esta sustenta um tipo de conhecimento que é interior e sempre se furtará à localização e à imagem.

\section{4.}

A teoria dos pontos de vista, a defesa da irredutibilidade da apercepção à representação, a consideração do princípio ontogenético do pensar estabelecido no esforço (único modo de dar conta do modo como "nasce" o pensamento para um sujeito, do que significa saber-se numa evidência aperceptiva, de como se individualizam as faculdades), resumem um mesmo ensejo: denunciar as inevitáveis perdas epistemológicas que resultam da transposição da inspiração físico-fisiológica para o âmbito da psicologia.

42 Discours, p. 64. Cf. DEVARIEUX, A. Maine de Biran. L'individualité persévérante, Millon, Grenoble, 2004, p. 111.

${ }^{43}$ Discours, p. 54

44 Ibidem, p. 54. 
Em tal diagnóstico biraniano de crise da ciência do homem, não deixará o leitor contemporâneo de filosofia de encontrar - ocasião para medir o alcance das teses de Biran - paralelos com a reflexão husserliana sobre a "crise das ciências europeias". De facto, parece-nos similar a indagação de Husserl no dealbar do século XX, ao constatar o triunfo de uma psicologia que se constituiu "sob a forma de uma matematização concebida como tarefa infinita"45. Crítico, perguntará o fenomenólogo: "pode o mundo e a existência humana nele, ter na verdade um sentido, se as ciências só admitem como verdadeiro aquilo que é deste modo objectivamente verificável (...)?"46 À distância no tempo, os dois filósofos unem-se num mesmo postulado: para Biran "o físico-simbólico", para Husserl "o matemático-simbólico (...) são índices expressos de um modo de travestir a presença do pensamento" ${ }^{47}$. E é nesse gesto, justamente, que Biran compreende ser o próprio lugar epistemológico do propriamente humano do homem que se pretende eliminar, o momento e a textura propriamente pessoal do pensar e da mediação de si que progressivamente se tenta ignorar na sua diferença, sob a pressão de uma putativa legibilidade integral do moral no físico, do interior no orgânico, do irrepresentável no localizável. Ricoeur, igualmente, dará voz às mesmas preocupações de Biran no contexto do seu diálogo célebre com J.P. Changeux. Respondendo ao seu interlocutor quando este afirma ser possível "identificar o psíquico vivido com o neuronal observado", o filósofo de Valence afirmará de modo inequívoco: "é aí que reside o problema e não a solução. Poderemos 'identificar' o psíquico vivido com o neuronal observado? ${ }^{48}$ Foi esta mesma pergunta que Biran não se cansou de lançar à neurologia de Bonnet, à ideologia fisiológica de Cabanis, à frenologia de Gall, à teoria das divisões das faculdades de Pinel e a todas as doutrinas do mesmo género. Todas essas doutrinas procura Biran confrontar com a opção metafísica implícita de que se nutrem, a saber: a presunção de que se explica (e se encontra primeiro) no jogo das fibras cerebrais, nas leis da organização, ou nas bossas do crânio, o que é da ordem de uma humanidade dupla. O que assim se esquece, notará Biran com acutilância, é a diferença entre interior e exterior, apercebido e representado, testemunhado (individualmente) e

45 MONTEBELLO; P., "Une individuation... », o. c., p. 83. Cf. HUSSERL, E., A Crise das Ciências Europeias e a Fenomenologia Transcendental (trad. port. de Diogo Falcão Ferrer), Phainomenon, Centro de Filosofia U. Lisboa, Lisboa, 2008, p. 36-37

${ }^{46}$ HUSSERL, E., A Crise das Ciências Europeias ..., o. c., p. 22.

${ }^{47}$ MONTEBELLO; P., "Une individuation... », o. c., p. 83.

48 CHANGEUX, Jean-Pierre et RICOEUR, Paul, Ce qui nous fait penser. La nature et la règle, Éditions Odile Jacob, Paris, 1998, p. 75. 
observado (por generalização); e nesse esquecimento é o problema da passagem de uma ordem a outra que inevitavelmente fica sem resposta.

Nessa zona de impensado nunca deixarão de florescer, segundo Biran, todas as assimilações infundadas "entre os fenómenos do $\mathrm{eu}$ individual"49 e uma "ordem de factos absolutamente estranhos ao $e u$ " 50 - ou, o que para o filósofo é o mesmo, não deixarão de abundar as propostas de metafísicos ou moralistas superficiais, que nos surpreendem com asserções, induções ligeiras, analogias ilusórias e explicações frívolas. ${ }^{51}$

\section{REFERÊNCIAS BIBLIOGRÁFICAS}

AZOUVI, F., Maine de Biran. La science de l'homme, Vrin, Paris, 1995.

CHANGEUX, Jean-Pierre et RICOEUR, Paul, Ce qui nous fait penser. La nature et la règle, Éditions Odile Jacob, Paris, 1998.

DEVARIEUX, A. Maine de Biran. L'individualité persévérante, Millon, Grenoble, 2004.

GUSDORF, G. La conscience révolutionnaire, Payot, Paris, 1978.

GUSDORF, G., Les principes de la pensée au siècle des Lumières, Payoy, Paris, 1971.

GOUHIER, H., Études sur l'histoire des idées en France depuis le XVIIe siècle, Vrin, Paris.

HENRY, M., Philosophie et phénoménologie du corps, P.U.F., Paris, 1987.

HUSSERL, E., A Crise das Ciências Europeias e a Fenomenologia Transcendental (trad. port. de Diogo Falcão Ferrer), Phainomenon, Centro de Filosofia U. Lisboa, Lisboa, 2008.

MADINIER, Gabriel, Conscience et mouvement: étude sur la philosophie française de Condillac a Bergson, Félix Alcan, Paris, 1938.

MAINE de BIRAN, Mémoire sur la décomposition de la pensée, in ID, Oeuvres de Maine de Biran (dir. F. Azouvi), t. III, Vrin, Paris, 1988.

MAINE de BIRAN, De l'aperception immédiate. Mémoire de Berlin,1807, in ID Oeuvres de Maine de Biran (dir. F. Azouvi), t. IV, Vrin, Paris, 1995.

MAINE de BIRAN, Discours à la société médicale de Bergerac, in ID, Oeuvres de Maine de Biran (dir. F. Azouvi), t. V, Vrin, Paris.

\footnotetext{
${ }^{49}$ Rapports, p. 86

${ }^{50}$ ID, o. c., 1. c.

${ }^{51}$ Cf. Rapports, p. 71.
} 
MAINE de BIRAN, Rapports du physique et du moral de l'homme, in ID, Oeuvres de Maine de Biran (dir. F. Azouvi), t. VI, Vrin, Paris, 1984.

MAINE de BIRAN, Essai sur les fondements de la psychologie et sur ses rapports avec l'étude de la nature, I, in ID, Oeuvres de Maine de Biran (dir. F. Azouvi), t. VII-1, Vrin, Paris, 2001.

MAINE de BIRAN, Dernière philosophie: existence et anthropologie, in ID Oeuvres de Maine de Biran (dir. F. Azouvi), t. X-2, Vrin, Paris, 1989.

MAINE de BIRAN, Commentaires et marginalia, Dix-septième siècle, in ID, Oeuvres de Maine de Biran (dir. F. Azouvi), t. XI-1, Vrin, Paris, 1990.

MAINE de BIRAN, Commentaires et marginalia, Dix-huitième siècle, in ID, Oeuvres de Maine de Biran (dir. F. Azouvi), t. XI-2, Vrin, Paris, 1993.

MAINE de BIRAN, Commentaires et marginalia, Dix-neuvième siècle, in ID, Oeuvres de Maine de Biran (dir. F. Azouvi), t. XI-3, Vrin, Paris.

MAINE de BIRAN, Correspondance philosophique, 1766-1804, in ID, Oeuvres de Maine de Biran (dir. F. Azouvi), t. XIII-2, Vrin, Paris, 1999.

MONTEBELlO, P. La décomposition de la pensée. Dualité et empirisme transcendantal chez Maine de Biran, Million, Grenoble: Millon, 1994.

MONTEBELLO; P., "Une individuation de la connaissance psycho-physique", in PETIT, Jean-Luc, Les neurosciences et la philosophie de l'action, Vrin, Paris, 1997, pp. 79-96.

MONTEBELlO, P., Nature et subjectivité, Millon, Grenoble, 2007.

MORAVIA, Sérgio, Il tramonto dell'iluminismo, Filosofia e Politica nella societá francese (1770-1810), Laterza, Bari, 1968.

RICOEUR, P., Soi-même comme un autre, Seuil, Paris, 1990. 
